\title{
Community pharmacists' involvement in smoking cessation: familiarity and implementation of the National smoking cessation guideline in Finland
}

\author{
Terhi Kurko ${ }^{1 *}{ }^{*}$, Kari Linden ${ }^{2 *}$, Kirsi Pietilä ${ }^{3}$, Patrick Sandström ${ }^{4}$, Marja Airaksinen ${ }^{1}$
}

\begin{abstract}
Background: Guidelines on smoking cessation (SC) emphasize healthcare cooperation and community pharmacists' involvement. This study explored the familiarity and implementation of the National SC Guideline in Finnish community pharmacies, factors relating to Guideline familiarity, implementation and provision of SC services.

Methods: A nationwide mail survey was sent to a systematic, sample of community pharmacy owners and staff pharmacists (total $n=2291)$. Response rate was $54 \%(n=1190)$. Factors related to the SC Guideline familiarity were assessed by bivariate and multivariate analysis.

Results: Almost half (47\%) of the respondents $(n=1190)$ were familiar with the SC Guideline and familiarity enhanced Guideline implementation. The familiarity was associated with the respondents' perceptions of their personal SC skills and knowledge (OR 3.8); of customers' value of counseling on nicotine replacement therapy (NRT) (OR 3.3); and regular use of a pocket card supporting SC counseling (OR 3.0). Pharmacists' workplaces' characteristics, such as size and geographical location were not associated with familiarity. In addition to recommending NRT, the pharmacists familiar with the Guideline used more frequently other Guideline-based SC methods, such as recommended non-pharmacological SC aids, compared to unfamiliar respondents.

Conclusions: SC Guideline familiarity and implementation is crucial for community pharmacists' involvement in SC actions in addition to selling NRT products. Pharmacists can constitute a potential public health resource in SC easily accessible throughout the country.
\end{abstract}

\section{Background}

Smoking cessation (SC) is one of the most effective ways to promote public health and reduce healthcare costs [1-5]. Health care professionals play a key role in SC $[1,4,5]$. To support SC, evidence-based guidelines have been established [4-7]. Despite this, SC does not routinely take place in healthcare in the recommended way [4,6-10]. Recent British and US guidelines on SC emphasize cooperation in healthcare and community pharmacists' involvement $[4,5]$. Correspondingly, the Finnish Current Care Guideline (later SC Guideline) published in 2002 and updated in 2006 has been

\footnotetext{
* Correspondence: terhi.a.kurko@helsinki.fi; kari.linden@pfizer.com

+ Contributed equally

${ }^{1}$ University of Helsinki, Faculty of Pharmacy, Division of Social Pharmacy,

Viikinkaari 9C, P.O Box 56, 00014 University of Helsinki, Finland

${ }^{2}$ Pfizer Oy, Helsinki, Finland
}

(C) 2010 Kurko et al; licensee BioMed Central Ltd. This is an Open Access article distributed under the terms of the Creative Commons Attribution License (http://creativecommons.org/licenses/by/2.0), which permits unrestricted use, distribution, and reproduction in any medium, provided the original work is properly cited.

developed from the multidisciplinary viewpoint by the Finnish Medical Society [7]. According to it, all healthcare professionals have specified SC responsibilities, and the local cooperation between them should facilitate SC by increasing and strengthening contacts with patients $[11,12]$.

Some studies of the implementation process of the SC guidelines have been made $[4,6,10,13]$. These studies and the literature on guideline implementation provide strong evidence that changing healthcare professionals' practices requires more effort than solely disseminating the guidelines; systematic efforts are needed to promote their usage [4,13-15]. Most of these studies are focused on physicians and their practices, and few studies have explored the implementation of guidelines among other healthcare professionals $[6,10,14,16-19]$. Community pharmacists' role in SC has been widely studied and 
according to the systematic reviews conducted, their participation in SC may increase cessation rates [20-22]. Still, community pharmacists could extent their participation in SC by several alternative actions (Additional file 1, Table S1) [8,23-27]. To our knowledge this is the first study exploring the implementation of a National SC guideline among them.

The Finnish healthcare system is largely based on the public healthcare system, which is complemented by private sector services [28]. The National public health policy has had a strong emphasis on preventive services $[28,29]$. SC has been one of the priorities in preventive healthcare, with the focus on strong socioeconomic gradient in smoking prevalence [30]. Local SC services are coordinated by the healthcare centers $[28,29]$.

Finnish community pharmacies are privately owned by pharmacists and highly regulated to emphasize public health goals in their operations [31]. Finnish community pharmacists have proactively developed professional services, particularly patient counseling on prescription and non-prescription medications [32]. A long-term strategic goal of the Association of Finnish Pharmacies (AFP; the association of pharmacy owners) has been to establish a network of specialized community pharmacists on major public health concerns coordinating local services for customers having asthma, diabetes or cardiovascular diseases [33]. These initiatives have been supported by authorities and there is evidence that they have been successful [32]. The Finnish medicine users value the Finnish pharmacy system and pharmacists are appreciated among the three most commonly used and reliable sources of medicines information in addition to physicians and patient information leaflets [34,35].

Finnish community pharmacists are strongly encouraged to be involved in SC by the SC Guideline [7]. The professional organizations, particularly the Association of Finnish Pharmacies, have actively supported community pharmacists' involvement in SC and the implementation of the SC Guideline, e.g., by national training campaigns and SC counseling aid materials [36].

The SC Guideline was developed by a multidisciplinary expert group and it is based on robust scientific evidence [7]. It provides background information on tobacco and smoking as a health risk. Furthermore, the Guideline introduces a wide range of interventions found effective in SC, which are applicable in various health care settings. It's recommendations are targeted to all health care professionals including community pharmacists (Additional File 2, Table S2). The Guideline is distributed nationwide by free internet access along with online education supporting its implementation.

The objective of this study was to explore the implementation of the National SC Guideline in Finnish community pharmacies, factors related to familiarity with it and its implementation, and actions taken to provide SC services.

\section{Methods \\ Study design}

The survey questionnaire was mailed to a systematic national sample of every second Finnish community pharmacist $(\mathrm{n}=2291)$, including pharmacy owners $(\mathrm{n}=$ $292)$ and staff pharmacists $(n=2235)$ in November 2006. The sample was systematically drawn from member registers of the three national pharmacists' professional associations. At the time of the survey, their registers covered $100 \%$ of the Finnish pharmacy owners and $93 \%$ of the staff pharmacists with B.Sc. (Pharm.) and M.Sc. (Pharm.) degree. Finnish pharmacy owners belong to the Association of Finnish Pharmacies (AFP). Staff pharmacists with a B.Sc (Pharm.) belong to the Finnish Pharmacists' Association and staff pharmacists with a M.Sc. (Pharm.) degree belong to either the Finnish Pharmacists' Association (FPA) (with 369 M.Sc. members at the time of the survey) or the Finnish Pharmacists' Society (FPS) (with 379 members). Thus, the survey was sent to $185 \mathrm{M} . \mathrm{Sc}$. members of FPA and to 190 M.Sc. members of FPS. For the statistical analysis all the received responses were combined.

After two reminders and one repeat questionnaire, we received responses from a total of 1190 community pharmacists, the final response rate being 54\% (Table 1). The respondents well represented the target population according to demographic characteristics, but respondents who specialized in the treatment of asthma, diabetes or cardiovascular diseases were of a higher percentage compared to those unspecialized in those fields (Table 1).

The study was conducted following scientific ethics [37]. To secure respondents anonymity, all the responses were handled in numeric form. No ethics committee's approval was required for this kind of study under the ethical guidelines of the University of Helsinki.

\section{Survey instrument}

The survey instrument was based on the literature on guideline dissemination and implementation $[6,13-16,38,39]$. As the familiarity with a guideline is the first step in implementation [15], one of the key questions in our survey was designed to assess just this. The structured question was adopted from earlier studies conducted among physicians and public health nurses (Sandström P et al. 2009, unpublished) and was modified for pharmacy practice as follows: "How familiar are you with the SC Guideline?" The following options were given: "I have read the Guideline through carefully; I am familiar with its main principles; I have glanced through it; I have heard about it"; and "I am not familiar with it". 
Table 1 Characteristics of the respondents $(n=1190)$ and the target population $(n=5053)$

\begin{tabular}{|c|c|c|c|c|c|}
\hline \multirow[t]{2}{*}{ Variable } & \multicolumn{2}{|c|}{$\begin{array}{l}\text { Respondents } \\
(\mathrm{n}=1190)\end{array}$} & \multicolumn{2}{|c|}{$\begin{array}{l}\text { Target population } \\
\quad(n=5053)\end{array}$} & \multirow[t]{2}{*}{$p$-value $* *$} \\
\hline & $\%$ & $\mathrm{n}$ & $\%$ & $\mathrm{n}$ & \\
\hline \multicolumn{6}{|c|}{ Variables associated with the respondent pharmacist } \\
\hline Professional status & & & & & 0.858 \\
\hline B.Sc. Pharmacist (Staff pharmacist) & 70 & 833 & 72 & 3654 & \\
\hline M.Sc. Pharmacist (Staff pharmacist) & 18 & 217 & 16 & 815 & \\
\hline Pharmacy owner & 12 & 140 & 12 & 584 & \\
\hline Total & 100 & 1190 & 100 & 5053 & \\
\hline Specialization of the respondent* & & & & & $<0.001$ \\
\hline Asthma & 25 & 272 & 14 & 706 & \\
\hline Diabetes & 21 & 230 & 13 & 680 & \\
\hline Cardiovascular diseases & 20 & 221 & 12 & 613 & \\
\hline \multicolumn{6}{|l|}{ Participation in continuing education in SC } \\
\hline In-house training & 48 & 568 & na & na & \\
\hline Continuing education (CE) & 25 & 302 & na & na & \\
\hline In-house training by a drug company & 40 & 477 & na & na & \\
\hline CE by a drug company & 33 & 398 & na & na & \\
\hline Not participated & 20 & 229 & na & na & \\
\hline \multicolumn{6}{|c|}{ Variables associated with the respondent's working place } \\
\hline Location by province & & & & & 0.790 \\
\hline Southern Finland & 39 & 459 & 41 & 2087 & \\
\hline Western Finland & 33 & 392 & 35 & 1773 & \\
\hline Eastern Finland & 15 & 174 & 12 & 604 & \\
\hline Northern Finland & 13 & 157 & 12 & 589 & \\
\hline Total & 100 & 1182 & 100 & 5053 & \\
\hline Annual prescription volume & & & & & 0.161 \\
\hline Less than 40000 & 21 & 252 & 16 & 782 & \\
\hline $40000-80000$ & 38 & 452 & 34 & 1751 & \\
\hline 80001 or more & 41 & 475 & 50 & 2520 & \\
\hline Total & 100 & 1179 & 100 & 5053 & \\
\hline Ownership & & & & & 0.295 \\
\hline Privately owned & 94 & 1108 & 91 & 4589 & \\
\hline University owned & 6 & 75 & 9 & 464 & \\
\hline Total & 100 & 1183 & 100 & 5053 & \\
\hline
\end{tabular}

* Based on the professional programs run by the AFP since late $1990 \mathrm{~s}$ to assure community pharmacies' contribution to the national public health goals. Information available on pharmacists working in privately owned community pharmacies (missing data from the two university owned pharmacies covering about $11 \%$ of the total prescription volume).

** Counted between the of respondents and the target population in relation to the background variable na $=$ not available

For the analysis the options "I have read the Guideline carefully through" and "I am familiar with its main principles" were combined to make up a group of respondents "Familiar with the Guideline." The remainder of the respondents was categorized as "Unfamiliar with the Guideline".

According to the Finnish SC Guideline, it is the duty of the pharmacy owners to arrange for sufficient SC training for their staff pharmacists (Additional file 2, Table S2) [7]. This was measured by asking respondents to assess their participation in continuing SC education (Tables 1,2 and 3). The SC Guideline was used as a basis for the measuring of SC actions taken at community pharmacies (Table 4). It recommends community pharmacists to ensure sufficient and rational use of SC medication and to support non-pharmacological SC [7]. This means that pharmacists are expected to assess individual customer's level of addiction to plan the treatment and its follow-up accordingly. They are also expected to recommend the use of non-pharmacological $\mathrm{SC}$ aids, such as written materials or internet portals. In our survey this was measured by a set of questions assessing the frequency of recommending Guidelinebased pharmacological and non-pharmacological SC 
Table 2 Proportion (\%) of the respondents familiar with the SC Guideline $(n=525)$

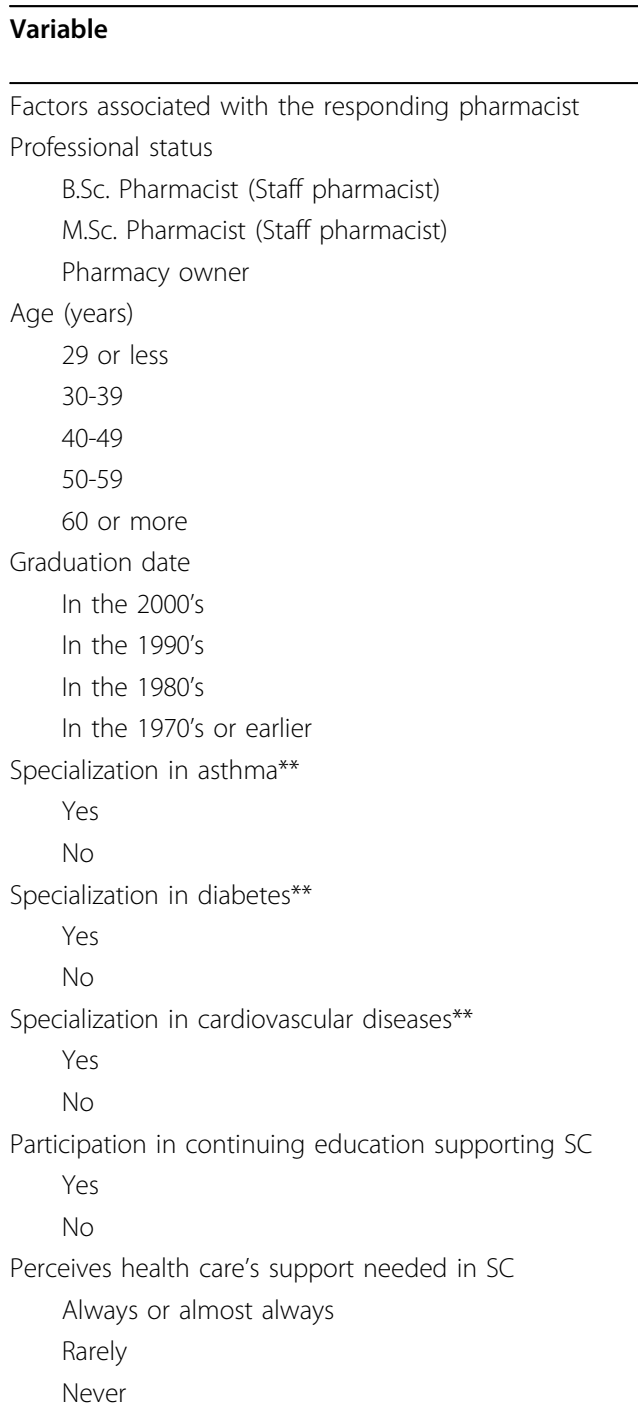

Perceives own personal skills and knowledge adequate to support SC

Agree

No opinion

Disagree

Perceives customers value of NRT counseling

\section{Agree}

No opinion

Disagree

Perceives cigarette's smoke extremely detrimental to health

(Scale: 1 = strongly disagree; $10=$ strongly agree)

$$
\text { Yes }
$$

No

Smoked at least 100 cigarettes up to date

Yes

No

Factors associated with the respondent's workplace

Location by province
Table 2 Proportion (\%) of the respondents familiar with the SC Guideline $(\mathbf{n}=\mathbf{5 2 5})$ (Continued)

\begin{tabular}{llll}
\hline Southern Finland & 47 & \\
Eastern Finland & 40 & \\
Western Finland & 42 & \\
Northern Finland & 53 & \\
Annual prescription volume & & 0.276 \\
Less than 40000 & 42 & \\
$40000-80000$ & 48 & \\
80001 or more & 44 & \\
Ownership & \multicolumn{3}{c}{0.990} \\
Privately owned & 45 & \\
University owned & 45 & \\
Dispensing counter design & \multicolumn{3}{c}{$<0.001$} \\
Traditional counter & 37 & \\
Sit-down counseling station & 48 & \\
Both in use & 51 & \\
\hline
\end{tabular}

SC services available in the respondent's workplace Individually tailored SC service
Yes 57

No 44

Smoking pass

Yes, used often $\quad 75$

Yes, used sometimes 61

No $\quad 46$

SC counseling supporting pocket card in use $\quad<0.001$

Yes, used often 64

Yes, used sometimes $\quad 48$

No 31

In-house guideline in NRT dispensing $\quad<0.001$

Yes, written guideline available $\quad 59$

Yes, oral guideline available $\quad 56$

No $\quad 36$

Participation in local multidisciplinary SC actions $\quad<0.001$ Yes 69

\begin{tabular}{ll} 
No & 39 \\
\hline Total (all the respondents) & 47
\end{tabular}

* Difference between the levels of each background variable.

**Based on the professional programs run by the AFP since late $1990 \mathrm{~s}$ to assure community pharmacies' contribution to the national public health goals. Information available on pharmacists working in privately owned community pharmacies (missing data from the two university owned pharmacies covering about $11 \%$ of the total prescription volume).

treatment options to the smoking pharmacy customers (Table 4).

In addition, the SC Guideline [7] expects pharmacists to be familiar with the Finnish version of the 5A's Intervention (6K's in Finnish) $[4,40]$. Respondents were asked about the use of the 5A's Intervention with the options: "Always; Often; With every second customer; Sometimes; Never." For the analysis, options "Always" and "Often" were reclassified as "At least often" (Table 4). The remaining options were categorized as "Not often". 
Table 3 Variables associated with the familiarity of SC Guideline in the multivariate analysis (logistic regression analysis)

\begin{tabular}{|c|c|c|c|c|}
\hline \multirow[t]{2}{*}{ Variable } & \multicolumn{2}{|c|}{ Unadjusted } & \multicolumn{2}{|c|}{ Adjusted* } \\
\hline & OR $(95 \% \mathrm{Cl})$ & p-value & OR $(95 \% \mathrm{Cl})$ & p-value \\
\hline \multicolumn{5}{|c|}{ Factors associated with the responding pharmacist } \\
\hline \multicolumn{5}{|c|}{ Specialization in asthma } \\
\hline No & 1.0 & & 1.0 & \\
\hline Yes & $2.3(1.8-3.1)$ & $<0.001$ & $2.1(1.5-3.0)$ & $<0.001$ \\
\hline \multicolumn{5}{|c|}{$\begin{array}{l}\text { Participation in education supporting } \\
\text { SC counselling }\end{array}$} \\
\hline No & 1.0 & & 1.0 & \\
\hline Yes & $3.3(2.4-4.7)$ & $<0.001$ & $2.1(1.5-3.1)$ & $<0.001$ \\
\hline \multicolumn{5}{|c|}{ Perceives health care's support needed in SC } \\
\hline Never & 1.0 & & 1.0 & \\
\hline Seldom & $2.6(1.2-5.7)$ & 0.010 & $2.0(0.9-5.0)$ & 0.104 \\
\hline Always or almost always & $4.3(1.9-9.4)$ & 0.021 & $2.7(1.2-6.6)$ & 0.022 \\
\hline \multicolumn{5}{|c|}{$\begin{array}{l}\text { Perceives own personal skills and knowledge } \\
\text { adequate to support SC }\end{array}$} \\
\hline No & 1.0 & & 1.0 & \\
\hline No opinion & $2.8(1.5-5.2)$ & 0.001 & $3.5(1.6-7.4)$ & 0.001 \\
\hline Yes & $5.0(3.1-7.9)$ & $<0.001$ & $3.8(2.2-6.5)$ & $<0.001$ \\
\hline \multicolumn{5}{|c|}{ Perceives customers value of NRT counseling } \\
\hline Disagree & 1.0 & & 1.0 & \\
\hline No opinion & $2.2(1.0-4.7)$ & 0.016 & 3.3(1.3-8.7) & 0.016 \\
\hline Agree & $2.4(1.2-4.5)$ & 0.044 & $2.3(1.0-5.4)$ & 0.044 \\
\hline \multicolumn{5}{|c|}{ Smoked at least 100 cigarettes up to date } \\
\hline No & 1.0 & & 1.0 & \\
\hline Yes & $1.5(1.1-1.9)$ & 0.003 & $1.7(1.2-2.3)$ & 0.001 \\
\hline \multicolumn{5}{|c|}{ SC services available in the respondent's workplace } \\
\hline \multicolumn{5}{|c|}{ SC counseling supporting pocket card in use } \\
\hline Never & 1.0 & & 1.0 & \\
\hline Sometimes & $2.0(1.5-2.6)$ & $<0.001$ & $1.7(1.3-2.4)$ & 0.002 \\
\hline Always & $3.9(2.8-5.5)$ & $<0.001$ & $3.0(2.0-4.4)$ & $<0.001$ \\
\hline \multicolumn{5}{|c|}{ In-house guideline in NRT dispensing in use } \\
\hline No & 1.0 & & 1.0 & \\
\hline Yes, oral & $2.3(1.7-3.1)$ & $<0.001$ & $1.5(1.0-2.1)$ & 0.030 \\
\hline Yes, written & $2.4(1.8-3.3)$ & $<0.001$ & $1.8(1.3-2.6)$ & 0.001 \\
\hline \multicolumn{5}{|c|}{$\begin{array}{l}\text { Participation in local multidisciplinary } \\
\text { SC actions }\end{array}$} \\
\hline No & 1.0 & & 1.0 & \\
\hline Yes & $3.5(2.5-4.8)$ & $<0.001$ & $2.4(1.6-3.5)$ & $<0.001$ \\
\hline
\end{tabular}

\section{Background variables}

The background variables used in this study were selected on the basis of the literature [13,15,16,38,39]. They were related to characteristics of the responding pharmacist; characteristics of his/her workplace; and SC actions that have taken place at his/her workplace (Table 2). This categorization of the background variables originates from the meta-review of Francke et al. (2008), in which guideline implementation was identified to be affected by factors related to guideline content, patient, healthcare professional and environment [15]. In addition to these variables, participation in local SC multidisciplinary teamwork was used as a background variable (Tables 2 and 3) for familiarity with the Guideline and measuring its implementation (Table 4).

All background variables for Guideline familiarity and implementation were used in their original format, except the one related to pharmacist's participation in continuing SC education (Table 1). It was reclassified as a dichotomic variable (yes/no) for the statistical analysis 
Table 4 Implementation of the SC Guideline-based actions among the pharmacists familiar and unfamiliar with the Guideline.

\begin{tabular}{|c|c|c|c|}
\hline SC Guideline based actions and services & $\begin{array}{l}\text { Familiar with the SC } \\
\text { Guideline }(n=512)\end{array}$ & $\begin{array}{l}\text { Unfamiliar with the SC } \\
\text { Guideline }(n=625)\end{array}$ & p-value* \\
\hline & $\%$ & $\%$ & \\
\hline \multicolumn{4}{|l|}{ Workplace involvement in local multidisciplinary SC actions } \\
\hline Participation in a joint training & 15 & 5 & $<0.001$ \\
\hline Considered joint practices & 12 & 5 & $<0.001$ \\
\hline Have joint practices & 5 & 2 & $<0.001$ \\
\hline \multicolumn{4}{|l|}{ Recommends SC Guideline-based pharmacological treatment } \\
\hline Nicotine gum & 94 & 96 & 0.450 \\
\hline Nicotine patch & 86 & 80 & 0.010 \\
\hline Nicotine inhaler & 22 & 20 & 0.345 \\
\hline Bupropion (Zyban ${ }^{\oplus)}$ & 15 & 10 & 0.080 \\
\hline \multicolumn{4}{|l|}{ Recommends SC Guideline-based non-pharmacological tools } \\
\hline Own quitting decision & 68 & 62 & 0.020 \\
\hline Written SC support material & 56 & 41 & $<0.001$ \\
\hline Participation in "Quit and Win" competition & 26 & 23 & 0.242 \\
\hline Support of family and/or friends & 17 & 14 & 0.120 \\
\hline Telephone-based SC support & 12 & 8 & 0.090 \\
\hline Pharmacy's individually tailored SC service & 10 & 6 & 0.006 \\
\hline Group therapy & 9 & 5 & 0.027 \\
\hline Internet-based SC support & 7 & 4 & 0.080 \\
\hline Advise to see a public health nurse & 4 & 3 & 0.104 \\
\hline \multicolumn{4}{|l|}{ Follows at "least often" ** the $5 A^{\prime}$ 's Intervention with smoking customers. } \\
\hline Advised to quit during the month prior the survey & 12 & 3 & $<0.001$ \\
\hline Told about how smoking effects medication during past month & 10 & 2 & $<0.001$ \\
\hline Asked about smoking during past week & 9 & 2 & $<0.001$ \\
\hline Assessed quitting date during past month & 2 & 1 & $<0.001$ \\
\hline \multicolumn{4}{|l|}{ Discusses always ${ }^{* * *}$ about smoking with customers who } \\
\hline Self-refer to their smoking & 94 & 91 & 0.101 \\
\hline are pregnant & 45 & 32 & $<0.001$ \\
\hline buy SC medicines & 35 & 17 & $<0.001$ \\
\hline suffer from a smoking-related disease & 18 & 7 & $<0.001$ \\
\hline
\end{tabular}

(Table 2). In the Likert-type statements measuring respondents' perceptions of the importance of SC and healthcare's role in it (Table 2), the options "Always" and "Almost always" were reclassified as "Always"; options "Strongly agree" and "Agree" to "Agree"; and correspondingly "Disagree" and "Strongly disagree" to "Disagree". The pharmacy's location by province was reclassified to four regions: Southern, Eastern, Western and Northern (combination of options Oulu and Lapland) Finland (Tables 1 and 2).

\section{Statistical analysis}

The statistical analysis was based on bivariate and multivariate analysis. The statistical significance in the bivariate analysis was tested by Chi Square test ( $p$-value of
$<0.05$ was considered statistically significant). In the multivariate analysis, logistic regression was applied to control for a concomitant effect of the background variables selected for the analysis on the basis of the bivariate analysis. The main outcome variable measuring respondents' familiarity with the Guideline was dichotomized $(1=$ Respondent familiar with the Guideline; $0=$ Unfamiliar). The Spearman's correlations between the background variables were calculated to avoid possible multicolinearity. Of the two variable pairs with a correlation co-efficient of 0.6 or more, (respondent's age and graduation year; and "Smoking pass in use" and "Pocket card to support SC counseling in use"), respondent's age and use of a SC pocket card were included in the regression analysis. A backward step-wise logistic 
regression analysis was conducted. The final model did not include interaction terms. The associations between the outcome and background variables were described by Odds Ratios calculated from the B-estimates, and p-values (Table 3). All the statistical analyses were conducted by the SPSS analytical software, version 15 (SPSS Inc., Chicago, IL).

\section{Results}

\section{Familiarity with the SC Guideline}

Almost half $(47 \%)$ of the responding pharmacists $(\mathrm{n}=$ 1190) were familiar with the SC Guideline (Table 2). In bivariate analysis, the following variables related to individual pharmacists' characteristics positively influenced the familiarity with the SC Guideline: specialization in asthma; ever smoked 100 or more cigarettes; participation in continuing SC education; being a pharmacy owner; and being older (Table 2). Also the following variables reflecting respondents' $\mathrm{SC}$ perceptions positively influenced the familiarity with the SC Guideline: healthcare's support needed in SC; own personal skills and knowledge adequate to support SC; perception that customers value NRT counseling; and perception that cigarette smoke is extremely detrimental to health (Table 2). Of the background variables related to respondent's working pharmacy, its location by province and dispensing counter design were associated with the Guideline familiarity (Table 2). All the variables measuring availability of $\mathrm{SC}$ services at the respondent's working pharmacy, e.g., use of SC pocket card, participation in local multidisciplinary SC actions, individually tailored SC service, and in-house guideline on NRT dispensing, were associated with the SC Guideline familiarity (Table 2).

In the multivariate analysis, nine out of the 21 variables were found to have a statistically significant association with the SC Guideline familiarity. The highest ORs were found in the variables related to own perception of the personal skills and knowledge in SC (OR $3.8)$; perception of customers value NRT counseling (OR 3.3); and regular use of the pocket card in SC counseling (OR 3.0; all variables, $\mathrm{p} \leq 0.001$ ) (Table 3).

\section{Guideline Familiarity and implementation of the SC Guideline-based actions}

Implementation of the Guideline-based SC actions and services were more common among the respondents familiar with the Guideline (Table 4). The familiarity with the Guideline was strongly associated with respondents' working pharmacy's participation in local multidisciplinary SC actions, the frequency of applying the $5 \mathrm{~A}$ 's Intervention with smoking customers and the discussion about SC with customers who have higher risk factors or buy SC medicines. These actions were not so commonly taken compared to recommending NRT gum or patch, which were reported by almost all respondents despite their Guideline familiarity. Similarly, nearly all the respondents reported, that they always discuss about SC with customers who spontaneously refer to his/her smoking. The same applies to supporting smoker's own quitting decision which was done by more than $60 \%$ of the respondents.

\section{Discussion}

This National study showed that approximately half $(47 \%)$ of the responding pharmacists were familiar with the Finnish SC Guideline [7]. The Guideline familiarity was positively associated with the pharmacist's positive perception towards SC and SC actions taken in their workplace. On the other hand, no variables related to the characteristics of the workplace, such as pharmacy's size or ownership, geographical location or dispensing counter design influenced SC Guideline familiarity.

Healthcare professionals' unfamiliarity with the existing guidelines or their contents is considered a major barrier for successful guideline implementation [15,38]. According to a survey conducted among community pharmacists in Iowa in 2002, only $10 \%$ of the respondents were familiar with the US SC Guideline (Additional File 1, Table S1) [23]. In our study, approximately half of the pharmacists were familiar with the Finnish SC Guideline, i.e., they reported to know its main principles or have even better knowledge of it. This is very much in line with the survey of Ward et al. [14] reporting about half of the responding physicians in Australia being familiar with a National SC guideline. Interestingly, in that study [14], even more physicians selfreported that they followed the SC guideline's major recommendations than indicated being familiar with it. We had an opposite result in this respect with less respondents reporting implementation than familiarity with the Guideline. However, we found that the Guideline familiarity was associated with its implementation. These results illustrate the challenging nature of guideline implementation and the difficulty to assess the actual implementation, which has been widely studied $[14-16,38,41]$. The findings may also indicate differences between health professionals in bringing the SC guidelines into daily practice. It would be interesting to compare the SC guidelines implementation among different healthcare professionals with a sound methodology that allows reliable comparison.

In our study, the SC Guideline familiarity was more common among pharmacists who perceived that healthcare professionals are always needed in SC and were satisfied with their own personal SC skills and knowledge. Also the perception that customers value their NRT counseling positively influenced the Guideline 
familiarity. This is parallel to earlier findings of healthcare professionals' high personal motivation and positive attitude enhancing guideline implementation $[6,16,38,39,42]$. Correspondingly, studies conducted among community pharmacists found the association between good professional self-esteem and current SC practice (Additional File 1, Table S1) [8,23-26]. Healthcare professional's knowledge and SC perceptions can be enhanced by effective SC education and training, which should also focus on improving their-self esteem and understanding of their crucial role in SC $[43,44]$. According to a German survey among physicians, the association between SC training received and level of SC activeness might be linear [10].

Motivation to implement the SC Guideline may also be influenced by the economic value of SC services and the sale of SC medicines, as well as their reimbursement status [10,27]. In Finland, NRT products were released for general sale in 2006 and this has remarkably decreased the NRT sales in community pharmacies [45]. Despite this, community pharmacy owners' and staff pharmacists' commitment to SC was strong one year after the deregulation. It would be interesting to make a follow-up study to assess the development of the motivation in the long term and to follow the Guideline implementation rate.

Our findings suggest that the SC Guideline familiarity does not influence the recommendation of NRT products to smoking customers, which was clearly the most common SC action taken place among all the respondents. However, the familiarity was associated with the use of more sophisticated SC methods, such as recommending non-pharmacological methods, use of 5A's Intervention and participation in local multidisciplinary SC actions. Similarly, a survey among Australian physicians found a high rate of NRT recommendation, whereas behavioral or quitting advice or quit date setting were far rare [6]. Though the SC Guideline underlines the importance of local multidisciplinary collaboration, it proved to be a rare in our study. This finding is in accordance with earlier findings in Finland [46]. These findings suggest that there is a lot of work needed in order to achieve the key aim of the SC Guideline - to promote multidisciplinary care. It would be interesting to find out whether the situation is the same in other countries.

Our responses indicate that customers' degree of initiative significantly influences community pharmacists' SC counseling activity. This is in line with previous studies conducted among pharmacists (Additional File 1, Table S1) [23,24]. Community pharmacists' familiarity with the SC Guideline particularly influences their counseling activity with customers being extremely vulnerable for tobacco use (e.g. pregnant women and those who suffer from smoking-related diseases). These findings underline the importance of making the SC Guideline widely known among pharmacists and other healthcare professionals if they are required to provide sophisticated SC services in their community.

According to several previous studies, the working place has an important role in enhancing guideline familiarity and implementation [13,15,38,39]. In our study, SC services available in the workplace increased the familiarity with the Guideline, whereas characteristics of the workplace, such as pharmacy's size and geographical location did not influence on it. These findings suggest that all Finns may have equal access to SC services provided by community pharmacies regardless of where they life. This is important from a public health viewpoint, and opposite to the recent findings from the USA; the study conducted in the pharmacies of New York City area found better availability and lower prices of NRT products in the pharmacies of the wealthiest living areas [47].

Our nationwide study based on a representative sample $(\mathrm{n}=1190)$ (Table 1$)$ of Finnish community pharmacists had a relatively high response rate (54\%) compared to other surveys conducted among community pharmacists $[8,20]$. There were no statistically significant differences between the respondent and target population with the following exception (Table 1). The pharmacists specialized in the treatment of asthma, diabetes or cardiovascular diseases, under the public health program of the AFP, responded more often than other pharmacists (see Methods, Context and study design, Table 1), this can be understood by their higher interest in SC and stronger professional role in SC. However, their proportion of the overall study respondents may overestimate the actual Guideline familiarity.

Respondents' familiarity with the SC Guideline was chosen to be our main outcome measure. We considered it to be more reliable for the respondents to assess their own familiarity with the Guideline than the actual level of implementation, which can be biased by limited ability to recall or by self-perceptions. In further studies, it might be useful to conduct an analysis using Guideline-based actions as the outcome variables and include Guideline familiarity alongside with other background variables to estimate the relative impact of Guideline familiarity on practice. However, the level of actual implementation can be more reliably assessed by population based intervention studies or pseudo patron studies.

Our survey was conducted in 2006 - 2007, i.e., about four years ago. Since then, tobacco control policy has changed in Finland supporting more smoke-free public areas, such as restaurants, workplaces and even municipalities. Also a new prescription medicine has been 
launched for SC in 2006. Despite these remarkable changes no follow-ups on effectiveness of SC or health care professionals practices has been recently conducted. It would be interesting to repeat this study to see whether any changes have taken place in this respect.

\section{Conclusions}

Nearly half of the Finnish community pharmacists were familiar with the National Current Care Guideline in SC at the time of our survey. Pharmacists' Guideline familiarity can be enhanced by supporting their positive perceptions towards cessation, its importance and by offering continuing education. Further, the workplace (pharmacy) has an important role by providing Guideline-based SC services, and thus, support pharmacists' activeness in SC. Pharmacists' good knowledge and selfesteem towards SC alongside with SC supportive inhouse practices at pharmacy are in crucial role while supporting the implementation. Among Guideline familiar pharmacists, the Guideline-based SC actions and services are better implemented than among respondents unfamiliar with the Guideline.

\section{Additional material}

Additional file 1: Table S1: Examples of studies showing community pharmacists' participation in SC. This file contains an additional table, providing information of the studies of community pharmacists participation in SC.

Additional file 2: Table S2: The Community pharmacists' duties in the treatment chain of SC according to the National SC Guideline [7]. This file contains an additional table proving information about the SC tasks the Guideline requires from community pharmacists.

\begin{abstract}
Acknowledgements
We would like to thank Vesa Jormanainen, M.D., M.Sc., (The Centre of Pharmacotherapy Development, Rohto, Finland) for his contribution to development of the instruments to assess Finnish health care professionals' perceptions on smoking and smoking cessation utilized in this study and his comments on the design and conduction of this study. We would like to thank Finnish Cultural Foundation and Pfizer Oy, Finland, for their grant and funding supporting this study. We would also like to express our gratitude to the Association of Finnish Pharmacies, Finnish. Pharmacists' Association, and Finnish Pharmacists' Society for providing the study sample from their member registers. We are grateful to Richard Stevenson, M.Sc., for linguistic help with the manuscript.
\end{abstract}

\section{Author details}

'University of Helsinki, Faculty of Pharmacy, Division of Social Pharmacy, Viikinkaari 9C, P.O Box 56, 00014 University of Helsinki, Finland. ${ }^{2}$ Pfizer Oy, Helsinki, Finland. ${ }^{3}$ Pharmacy of Malmi, Helsinki, Finland. ${ }^{4}$ The National Institute of Health and Welfare, Helsinki, Finland.

\section{Authors' contributions}

All the authors meet the authorship criteria set by BMC Public Health. TK and $\mathrm{KL}$ conceptualized the study, did the statistical and other analysis, interpreted the findings and wrote the first draft. KP and PS contributed for the study design and for the development of the survey instrument. MA supervised all the steps of the research project and actively contributed to the preparation of this manuscript. All the authors have read and approved the final manuscript.

\section{Competing interests}

Terhi Kurko has received personal grant for this study from the Finnish Cultural Foundation and funding from Pfizer Oy, Finland. Kari Linden, Ph.D., M.Sc., is employed by Pfizer Oy, Finland. He was earlier employed by the Association of Finnish Pharmacies where he contributed to the implementation of the National Current Care Guideline on Smoking Cessation among community pharmacists. Kirsi Pietilä, Ph.D., is a Pharmacy Owner and former Senior Lecturer in Social Pharmacy at the Faculty of Pharmacy, University of Helsinki, Finland. Doctor Pietilä belongs to the working group of the National SC Guideline. Patrick Sandström is employed by the National Institute for Health and Welfare (THL). He and Professor Marja Airaksinen, Ph.D., have no conflict of interests.

Received: 28 April 2010 Accepted: 29 July 2010 Published: 29 July 2010

\section{References}

1. World Health Organization: WHO European strategy for smoking cessation policy. European tobacco control policy series, 1 Copenhagen: World Health Organization 2004.

2. Cromwell J, Bartosch WJ, Fiore MC Hasselblad V, Baker T: Cost-effectiveness of the clinical practice recommendations in the AHCPR guideline for smoking cessation. JAMA 1997, 278:1759-1766.

3. Parrot S, Godfrey C: Economics of smoking cessation. BMJ 2004, 328:947-949.

4. Fiore MC, Jaén CR, Baker TB, Bailey WC, Curry SJ, et al: Treating Tobacco Use and Dependence: 2008 Update Rockville, MD: US Dept of Health and Human Services 2008.

5. National Institute for Health and Clinical Excellence (NICE): Smoking cessation services in primary care, pharmacies, local authorities and workplaces, particularly for manual working groups, pregnant women and hard to reach communities. NICE public health guidance 10 London: National Institute for Health and Clinical Excellence 2008 [http://www.nice.org.uk] PH010].

6. Young JM, Ward JE: Implementing guidelines for smoking cessation advice in Australian general practice: opinions, current practices, readiness to change and perceived barriers. Fam Pract 2001, 18:14-20.

7. Working group set up by the Finnish Medical Society Duodecim and the Finnish Association for General Practice: Tupakointi, nikotiiniriippuvuus ja vieroitushoidot. Käypä hoito -suositus; 2002, updated version 2006, [in Finnish] http://www.kaypahoito.fi/web/kh/suositukset/naytaartikkeli/tunnus/hoi40020 (In English: Smoking, nicotine dependency and nicotine withdrawal. Current Care Summary; 2007). http://www.kaypahoito.fi/web/kh/suositukset/ naytaartikkeli/tunnus/ccs00026).

8. Hudmon KS, Prokhorov AV, Corelli RL: Tobacco cessation counselling: pharmacists' opinions and practices. Patient Educ Couns 2006, 61:152-160

9. Ferketich AK, Khan Y, Wewers ME: Are physicians asking about tobacco use and assisting with cessation? Results from the 2001-2004 national ambulatory medical care survey (NAMCS). Prev Med 2006, 43:472-476.

10. Twardella D, Brenner H: Lack of training as a central barrier to the promotion of smoking cessation: a survey among general practitioners in Germany. Eur J Publ Health 2005, 15:140-145.

11. Schmitt MH: Collaboration improves the quality of care: methodological challenges and evidence from US Health Care Research. $J$ Interprof Care 2001, 15:47-66.

12. An LC, Foldes SS, Alesci NL, Bland PC, Davern ME, Schillo BA, Ahluwalia JS, Manley MW: The impact of smoking-cessation intervention by multiple health professionals. Am J Prev Med 2008, 34:54-60.

13. Stone TT, Longo DR, Philipps RL, Hewett JE, Riley SL: Health care system and insurer support for smoking cessation guideline implementation. $J$ Health Care Finance 2002, 29:78-86.

14. Ward MW, Vaughn TE, Uden-Holman T, Doebbeling BN, Clarke WR, Woolson RF: Physicians' knowledge, attitudes and practices regarding a widely implemented guideline. J Eval Clin Pract 2002, 8:155-162.

15. Francke AL, Smit MC, De Veer A JE, Mistiaen P: Factors influencing the implementation of clinical guidelines for health care professionals: a systematic meta-review. BMC Med Inform Decis Making 2008, 8:38 [http:// www.biomedcentral.com/1472-6947/8/38]. 
16. Prior M, Guerin M, Grimmer-Somers K: The effectiveness of clinical guideline implementation strategies - a synthesis of systematic review findings. J Eval Clin Pract 2008, 14:888-897.

17. Hartmann KE, Payne P, Salisbury K, Jackson RD, Melvin CL: Best practice smoking cessation intervention and resource needs of prenatal care providers. Obstet Gynecol 2007, 110:765-770.

18. Studts JL, Burris $J$, Kearns DK, Worth $C T$, Sorrell CL: Providers practice prevention: promoting dental hygienists' use of evidence-based treatment of tobacco use and dependence. J Dent Educ 2009, 73:1069-1082.

19. Katz DA, Muehlenbruch DR, Brown RB, Fiore MC, Baker TB: Effectiveness of a clinic-based strategy for implementing the AHRQ smoking cessation guideline in primary care. Prev Med 2002, 35:293-301.

20. Sinclair HK, Bond CM, Stead LF: Community pharmacy personnel interventions for smoking cessation. Cochrane Database Syst Rev 2004, CD003698.

21. Dent LA, Harris KJ, Noonan CW: Tobacco Interventions Delivered by Pharmacists: a summary and systematic review. Pharmacother 2007, 27:1040-1051.

22. Cramp GJ, Mitchell C, Steer C, Pfleger S: An evaluation of a rural community pharmacy-based smoking cessation counseling and nicotine replacement therapy intiative. Int J Pharm Pract 2007, 15:113-121.

23. Aquilino ML, Farris KB, Zillich AJ, Lowe JB: Smoking-cessation services in lowa community pharmacies. Pharmacother 2003, 23:666-673.

24. Brewster JM, Ashley MJ, Laurier CL, Diose R, Victor C, Ferrence R, Cohen J: On the front line of smoking cessation: Pharmacists practices and selfperception. CPJ/RPC 2005, 138:32-38.

25. Goniewicz ML, Lingas EO, Czogala J, Koszowski B, Zielenska-Danch W, Sobczak A: The role of pharmacists in smoking cessation in Poland. Eval Health Prof 2010, 33:81-95.

26. Thananithisak C, Nimpitakpong P, Chaiyakunapruk N: Activities and perceptions of pharmacists providing tobacco control services in community pharmacy in Thailand. Nic Tob Res 2008, 10:921-925.

27. Brock T, Taylor D, Wuliji T: Curbing the tobacco pandemic: the global role for pharmacy London: The School of Pharmacy, University of London; and the Hague International Pharmaceutical Federation (FIP) 2007 [http://www. pharmacy.ac.uk/fileadmin/images/news_events/taylorFIP.pdf].

28. Vuorenkoski L: Restructuring municipal services - follow up. Health Policy Monitor 2008 [http://www.hpm.org/en/Surveys/THL___Finland/11/ Restructuring_municipal_services__follow_up.html].

29. Ministry of Social Affairs and Health: Primary Health Care Act 1972 (and revisions) [http://www.finlex.fi/en/laki/kaannokset/1972/en19720066.pdf].

30. Ministry of Social Affairs and Health: National action plan to reduce health inequalities 2008-2011 Helsinki: Ministry of Social Affairs and Health 2008 [http://www.teroka.fi/teroka/uploadfiles/tervero_ohjelma.pdf].

31. Ministry of Social Affairs and Health: Medicines Act and Decree and Amendments 1987, Unofficial translation in English: http://www.laakelaitos.fi/ legislation/national_legislation.

32. Puumalainen I: Development of Instruments to Measure the Quality of Patient Counselling. Doctoral dissertation Faculty of Pharmacy, the University of Kuopio 2005.

33. The Association of Finnish Pharmacies: Guidelines for professional community pharmacy. [in Finnish] Helsinki: The Association of Finnish Pharmacies 1997.

34. Närhi U: Sources of medicine information and their reliability evaluated by medicine users. Pharm World Sci 2007, 29:688-694.

35. Pohjanoksa M, Bell S, Helakorpi S, Närhi U, Pelkonen A, Airaksinen M: Is the internet replacing health professionals? A population survey of sources of medicine information among people with mental disorders. SoC Psychiatry Psychiatr Epidemiol.

36. The Association of Finnish Pharmacies: Action Plan community pharmacies supporting smoking cessation. [in Finnish] Helsinki: The Association of Finnish Pharmacies 2008 [http://www.apteekkariliitto.fi/Documents/ Toimenpideohjelma\%20tupakasta\%20vieroitus.pdf].

37. World Medical Association: Declaration of Helsinki - ethical principles for medical research involving human subjects [http://www.wma.net/en/ 30publications/10policies/b3/index.html].

38. Cabana MD, Rand CS, Powe NR, Wu AW, Wilson M, Abboud PAC, Rubin HR: Why don't physicians follow clinical practice guidelines?: a framework for improvement. JAMA 1999, 282:1458-1465.
39. Cooke M: The dissemination of a smoking cessation program: predictors of program awareness, adoption and maintenance. Health Promot Int 2000, 15:113-122.

40. American Psychiatric Association: Practice guideline for the treatment of patients with nicotine dependence. Am J Psychiatry 1996, 153(Suppl 10): s1-s31.

41. Grimshaw JM, Russell IT: Effect of clinical guidelines on medical practice: a systematic review of rigorous evaluations. Lancet 1993, 342:1317-1322.

42. Flores $G$, Lee $H$, Bauchner $H$, Kastner B: Pediatrician's attitudes, beliefs and practices regarding clinical practice guidelines: A national survey. Pediatrics 2000, 105:496-501.

43. Pbret $\mathrm{L}$ : Healthcare provider training in tobacco treatment: building competency. Am J Med Sci 2003, 326:242-247.

44. Sheffer CE, Barone CP, Anders ME: Training health care providers in the treatment of tobacco use and dependence: pre- and post-training results. J Eval Clin Pract 2009, 15:607-13.

45. Kurko T, Linden K, Vasama M, Pietila K, Airaksinen M: Nicotine replacement therapy practices in Finland one year after deregulation of the product sales - Has anything changed from the community pharmacy perspective? Health Policy 2009, 91:277-285.

46. Sandström P, Leppänen A, Simonen O: Organisation and practises of tobacco cessation services. [In Finnish] Ministry of Social Affairs and Health 2009, 15.

47. Bernstein SL, Cabral L, Maantay J, Pebrah D, Lounsbury D, Maroko A Murphy M, Shelley D: Disparities in access to over-the-counter nicotine replacement products in New York City pharmacies. Am J Public Health 2009, 99:1699-1704.

\section{Pre-publication history}

The pre-publication history for this paper can be accessed here: http://www.biomedcentral.com/1471-2458/10/444/prepub

doi:10.1186/1471-2458-10-444

Cite this article as: Kurko et al.: Community pharmacists' involvement in smoking cessation: familiarity and implementation of the National smoking cessation guideline in Finland. BMC Public Health 2010 10:444.

\section{Submit your next manuscript to BioMed Central and take full advantage of:}

- Convenient online submission

- Thorough peer review

- No space constraints or color figure charges

- Immediate publication on acceptance

- Inclusion in PubMed, CAS, Scopus and Google Scholar

- Research which is freely available for redistribution

Submit your manuscript at www.biomedcentral.com/submit
C) Biomed Central 